\title{
The outcomes of COVID-19 measures in a hyperbaric oxygen therapy centre during the pandemic
}

\author{
Kubra Ozgok-Kangal ${ }^{1} \oplus$, Taylan Zaman ${ }^{1} \oplus$, Bayram Koc ${ }^{2}$ \\ ${ }^{1}$ Department of Undersea and Hyperbaric Medicine, Gulhane Training and Research Hospital, \\ University of Health Science, Ankara, Turkey \\ ${ }^{2}$ Department of Internal Medicine, Gulhane Training and Research Hospital, University of Health Sciences, Ankara, Turkey
}

\begin{abstract}
Background: A hyperbaric oxygen (HBO) treatment session carries a high risk for severe acute respiratory syndrome coronavirus 2 (SARS-CoV-2) transmission since patients stay in a closed area for 2 hours. The primary aim of this study was to evaluate the effects of the preventive measures taken in the HBO centre. Materials and methods: This study evaluated the measures taken during the coronavirus disease 2019 (COVID-19) pandemic for multiplace hyperbaric chamber operated in department (Health Sciences University-Gulhane Research and Training Hospital, Ankara, Turkey) between March $16^{\text {th }}, 2020$ and December $31^{\text {st }}$, 2020. The medical records of patients who underwent $H B O$ treatment during this period were evaluated retrospectively. Their demographic attributes, the presence of risk factors, HBO indications, HBO session data, and COVID-19 inquiry forms were analysed.

Results: A total of 122 patients underwent $H B O$ treatment, and 150 people were subjected to pressure tolerance test (PTT). No COVID-19 case was treated with HBO in our department. The hyperbaric chamber was operated 608 times in total. Of these, 9.7\% $(n=59)$ procedures were carried out under emergency conditions, and 10\% ( $n=61)$ were PTTs. Accordingly, 59.8\% $(n=73)$ of the HBO-treated patients were considered at risk for a severe clinical presentation of SARS-COV-2. SARS-CoV-2 was detected in $5.7 \%$ $(n=7)$ of the HBO-treated patients during the HBO treatment period. Besides, two inside attendants (14.3\%) were diagnosed with COVID-19. There were only two concurrent cases in the same session among SARS-CoV-2 positive cases. The records revealed that these patients were sitting three seats away from each other. Another patient was sitting in between the two infected patients but was not diagnosed with SARS-CoV-2.

Conclusions: There is no clear evidence that these two patients infected each other; on the contrary, since no other patient was infected with SARS-CoV-2 in the same session, we may suspect that the infections were coincidental. The measures taken in our department seem to suffice in preventing in-session transmission of COVID-19 and similar infectious diseases in an HBO centre.
\end{abstract}

(Int Marit Health 2021; 72, 3: 228-236)

Key words: hyperbaric oxygen, COVID-19, SARS-CoV-2, transmission, measures

\section{INTRODUCTION}

A new type of coronavirus was reported as the cause of a series of pneumonia cases in Wuhan city in the Hubei province, China in 2019. Starting from China, it rapidly spread to other countries and created a global emergency by causing a huge increase in the number of cases worldwide. The World Health Organization (WHO) announced that the official name of the new infection would be COVID-19 disease, which stands for "2019 coronavirus" in February 2020 [1-3]. The pathogen responsible for the infection was

\section{Dr. Kubra Ozgok-Kangal, Department of Undersea and Hyperbaric Medicine, Gülhane Training and Research Hospital, Health Science University, Ankara, SBÜ-Gülhane}

Eğitim ve Araştırma Hastanesi, Sualtı Hekimliği ve Hiperbarik Tıp Kliniği, Etlik, 06010 Ankara, Turkey, e-mail: kubra_ozgk@hotmail.com 
named severe acute respiratory syndrome coronavirus 2 (SARS-CoV-2) by the International Committee on Virus Taxonomy (ICTV) since the genome of the newly identified virus is very similar to severe acute respiratory syndrome coronavirus (SARS-CoV) [4].

Patients infected with SARS-CoV-2 may show symptoms such as dry cough, fever, headache and shortness of breath, and some patients may get diagnosed with viral pneumonia $[5,6]$. Besides, asymptomatic cases have also been reported $[7,8]$.

SARS-CoV-2 is mainly spread by droplet transmission [9]. Transmission is believed to mainly occur by close-distance contact (approx. 6 feet or $2 \mathrm{~m}$ ) through inhalation of respiratory particles. When an infected person coughs, sneezes, or speaks, the virus, which spreads through respiratory secretions, may infect others when inhaled or by direct contact with mucosal membranes. Although contaminated surfaces are not believed to be the primary mode of transmission, it is possible that a person may get infected by touching contaminated surfaces. .

SARS-CoV-2 can be transmitted long distances by air (by inhaling airborne particles), yet it is disputable how this transmission mode affects the pandemic [10-13]. The study on SARS-CoV-2 transmission (e.g., in a restaurant or a bus) underlined the potential of airborne infection at longer distances in poorly ventilated environments [14-16].

The sessions in multiplace hyperbaric chambers are performed under direct supervision of a health care professional (an inside attendant) employed at our hyperbaric oxygen (HBO) treatment department. Although the masks and other personal protective equipment used during the treatment in all centres are carefully cleaned and disinfected, HBO treatment creates a risk of coronavirus cross-infection among patients participating in the same session. This is a serious cause for concern for the patients receiving HBO treatment since most of them are elderly people with comorbidities or immunosuppressed patients.

With a view to respond to the newly emerging threats new measures should be considered in HBO treatment centres. With the onset of the pandemic, the European Committee for Hyperbaric Medicine (ECHM) Society and Undersea and Hyperbaric Medicine Society (UHMS) in the United states of America (USA) have published recommendation reports discussing issues such as patient selection for HBO treatment, precautions to be taken during the session or cleaning of the pressure chamber $[17,18]$. In line with these reports, the location of the treatment centre, the urgency of HBO treatment, the age and general condition of the patient, dimensions of the pressure chamber, and the possibility to maintain social distance between patients should be evaluated carefully before patients are qualified for HBO treatment.
We, as Health Sciences University Gulhane Research and Training Hospital, Undersea and Hyperbaric Medicine Department, are providing services to Ankara and neighbouring provinces. Our clinic has one multiplace hyperbaric chamber. As a rule, a routine HBO treatment performed in the multiplace hyperbaric chamber takes 2 hours, there are 11 patients and one inside attendant in each session. Every day, there are three HBO treatment sessions performed in our department. With the onset of the pandemic, appropriate preventive measures have been introduced in all clinics of our hospital. However, due to the nature of HBO treatment (12 people staying close to one another for 2 hours) we had to implement some additional preventive measures. Besides the general measures proposed by the Infection Control Committee at our hospital, the Undersea and Hyperbaric Medicine Department has taken additional preventive measures in line with the guidelines recommended in ECHM and the UHMS reports; the restrictions are still being followed in our department. We believe it is essential to share the information on the preventive measures with regard to personnel safety, patient safety, COVID-19 transmission which we had implemented in our clinic at the beginning of the pandemic, in order to determine their effectiveness. It is important to share our department's experience with others because HBO treatment requires a different set of preventive measures than other treatment modalities especially that there are relatively few $\mathrm{HBO}$ treatment centres in our country and abroad in comparison to other health care centres.

The primary aim of this study was to evaluate the SARS-CoV-2 transmission inside the hyperbaric chamber during HBO treatment sessions despite preventive measures by determining the number of COVID-19 cases among patients undergoing $\mathrm{HBO}$ treatment as well as among inside attendants supervising the $\mathrm{HBO}$ sessions.

\section{MATERIALS AND METHODS}

This study evaluated the measures taken in the course of the COVID-19 pandemic at the Health Sciences University, Gulhane Research and Training Hospital, Undersea and Hyperbaric Medicine Department (Ankara, Turkey) between March $16^{\text {th }}, 2020$, and December $31^{\text {st }}, 2020$. All measures adopted between the dates mentioned will be presented in detail in the Results section. The number of $\mathrm{HBO}$ sessions, demographic data of patients who underwent $\mathrm{HBO}$ treatments, and the $\mathrm{HBO}$ treatment indications were analysed. The medical records of the patients were analysed retrospectively, and their demographic attributes, the presence of COVID-19 risk factors (chronic diseases, smoking, obesity, age over 65 years), HBO treatment indications, HBO treatment session data (the lists of patients and inside attendants) and COVID-19 inquiry forms were analysed. 
Table 1. The decisions on the continuation of treatment plans upon the official announcement of the first COVID-19 case announcement in our country

\begin{tabular}{|c|c|c|c|c|c|}
\hline Indications & $\begin{array}{l}\text { Patients whose } \\
\text { treatment was } \\
\text { terminated }(\mathrm{n})\end{array}$ & $\begin{array}{l}\text { Patients whose tre- } \\
\text { atment was suspen- } \\
\text { ded for } 3 \text { weeks (n) }\end{array}$ & $\begin{array}{l}\text { Patients whose tre- } \\
\text { atment was suspen- } \\
\text { ded for a week (n) }\end{array}$ & $\begin{array}{l}\text { Patients who- } \\
\text { se treatment } \\
\text { continued (n) }\end{array}$ & $\begin{array}{l}\text { Total number } \\
\text { of patients } \\
\text { (n) }\end{array}$ \\
\hline Diabetic foot ulceration & 3 & 5 & 0 & 2 & 10 \\
\hline Other chronic wounds & 3 & 2 & 0 & 0 & 5 \\
\hline $\begin{array}{l}\text { Chronic refractory } \\
\text { osteomyelitis }\end{array}$ & 1 & 2 & 0 & 1 & 4 \\
\hline $\begin{array}{l}\text { Sudden sensorineural } \\
\text { hearing loss }\end{array}$ & 0 & 0 & 1 & 2 & 3 \\
\hline Prosthesis infection & 1 & 2 & 0 & 0 & 3 \\
\hline Crush injury & 1 & 0 & 0 & 1 & 2 \\
\hline Avascular necrosis & 0 & 1 & 0 & 0 & 1 \\
\hline Psoas abscess & 0 & 0 & 0 & 1 & 1 \\
\hline Spondylodiscitis & 0 & 1 & 0 & 0 & 1 \\
\hline Total number of patients & 9 & 13 & 1 & 7 & 30 \\
\hline
\end{tabular}

We have chosen not to include the demographic data of patients who underwent pressure tolerance test (PTT) in our department as the PTT takes no more than 10 minutes and is performed once only. We have, however, included the data regarding the overall number of PTT sessions carried out during the study period.

The ethical approval was obtained from Health Sciences University- Gulhane Research and Training Hospital Non-Invasive Research Ethics Committee (Ankara, Turkey, number of approval: 2020-505, date: 29/12/2020 ).

\section{PARTICIPANTS}

The participants were the patients who underwent HBO treatment and inside attendants who participated in HBO sessions between 16.03.2020 and 31.12.2020 at our department.

\section{STATISTICAL ANALYSIS}

We used IBM SPSS Statistics version 21 (IBM Corp., Armonk, New York, USA) for statistical analysis. The data were presented as number (\%). The data which were normally distributed were expressed as mean \pm standard deviation. The data which were not normally distributed were expressed as median (minimum-maximum). The normal distribution of the data were analysed with The Kolmogorov-Smirnov test. However, due to a low number of positive COVID-19 cases, further statistical analysis was not possible. A p-value less than 0.05 were considered as statistically significant.

\section{RESULTS}

The first official SARS-CoV-2 case in our country was reported on March $11^{\text {th }}, 2020$. Three routine sessions were performed on that day in the Health Sciences University, Gulhane Research and Training Hospital, Undersea and Hyperbaric Medicine Department (Ankara, Turkey), each session including 10 patients. Upon the official announcement of the first case, a clinical meeting was held on March $17^{\text {th }}, 2020$, and treatment options for the patients with SARS-CoV-2 risk factors were discussed. All patients were informed about the risk of SARS-CoV-2 transmission during $\mathrm{HBO}$ session. A decision was taken to discontinue treatment of 9 out of 30 patients. In addition, the treatment of a patient with sudden hearing loss was suspended for a week, and the treatments of 13 other patients were suspended for 3 weeks. Detailed data of these patients are given in Table 1.

We decided to continue treatment of seven patients only. Starting from March $17^{\text {th }}, 2020$, HBO sessions in our clinic were organized twice a day, each session including 7 patients. The measures taken in our clinic to prevent the transmission of COVID-19 are summarised in Table 2. These measures were put into action 5 days after the first case of COVID-19 was officially confirmed. In the course of the pandemic, the initially introduced preventive measures were changed twice. Firstly, the inside attendants were admitted to accompany the sessions at the end of the first month of the pandemic. However, they had to stay in the personnel lock and were not allowed to enter the main chamber during the sessions. Inside attendants were obliged to wear N95 masks and face shield for protection as well as a safety uniform with gloves in case any intervention to the patients is necessary. Secondly, a detailed COVID-19 checklist to be completed before each HBO session was drawn up. On the other hand, disinfectants placed around the hyperbaric 
Table 2. Precautions inside the hyperbaric chamber against COVID-19 transmission in the department (Health Sciences University, Gulhane Research and Training Hospital, Undersea and Hyperbaric Medicine Department)

1. Patients are seated with at least one empty seat in between to provide a minimum of 1-metre social distance inside the hyperbaric chamber

2. The disinfection procedure is repeated after each $\mathrm{HBO}$ sessions and then the chamber is ventilated.

3. Patients must use hand sanitizer or wash their hands with soap for at least 20 seconds just before and after the HBO sessions.

4. The names of the patients are written on the lockers where their masks are kept and a special locker is reserved for each patient. No partition changes will be made until HBO therapy is completed.

5. Patients' masks will be washed, rinsed with soapy water and dried every day. While being dried, they cannot touch one another. The masks are sterilised once a week.

6. Before each $\mathrm{HBO}$ session, the temperature of each patient will be measured and they will be asked about any recent symptoms and COVID-19 contact history.

7. Any suspected patient will not be accepted to the hyperbaric chamber and will be referred to the COVID-19 outpatient clinic immediately.

8. The patients have to continue in the same HBO session until the treatment ends. There will be no changes in the session arrangements of the patients.

9. When there is a patient diagnosed with COVID-19, no new patient will be enrolled in that session for the following week. Other patients can continue HBO treatment but will be closely monitored for COVID-19. Patients will be informed and referred for PCR testing if they wish.

10. Patients will be seated in the chamber one by one. It is forbidden for patients to touch anything other than their seat. It is forbidden for patients to change seats after they have sat down.

11. The inside attendant will not accompany the patients inside the hyperbaric chamber. He/She will wait outside the hyperbaric chamber, and in case of an emergency, he/she will enter the hyperbaric chamber from the personnel locker with N95 mask, visor, surgical uniform and gloves on.

12. Only one person can accompany the patient while the patient is seated in the hyperbaric chamber.

COVID-19 - coronavirus disease 2019; HBO - hyperbaric oxygen; PCR - polymerase chain reaction

chamber have been removed to reduce the risk of fire due to high oxygen concentration. There have been no other changes to other preventive measures.

A total of 122 patients underwent HBO treatment sessions, and another 150 people were subjected to PTT, thus, the hyperbaric chamber was operated 608 times between March $16^{\text {th }}, 2020$, and December $31^{\text {st }}, 2020$. Of these, 9.7\% $(n=59)$ sessions were carried out under emergency conditions, and 10\% (61 times) were PTTs. The number of sessions carried out in each month is given in Figure 1.

Demographic attributes of 122 patients receiving HBO treatment in our clinic between March $16^{\text {th }}, 2020$, and December $12^{\text {th }}, 2020$ are given in Table 3 . The presence of a chronic disease, smoking, obesity (body mass index 30 and above), or age 65 years and above are considered to be a significant risk factor for severe clinical presentation of SARS-CoV-2 [19]. Accordingly, 59.8\% ( $n=73)$ of the HBO-treated patients were considered at risk for a severe clinical presentation of SARS-CoV-2. Among the patients considered not to be at risk, 3 patients were pregnant, and 5 patients were receiving temporary steroid treatment due to sudden hearing loss. The distribution of the patients by HBO indications is shown in Figure 2.

Any patients diagnosed with SARS-CoV-2 or suspected of the infection were excluded from HBO treatment ses- sions or PTTs. SARS-CoV-2 was detected in $5.7 \%(n=7)$ of the HBO-treated patients and 2 of 14 inside attendants $(14.3 \%)$ in the study period (Table 4). HBO treatment of the patients diagnosed with SARS-CoV-2 or those in contact with SARS-CoV-2-infected individuals was discontinued; (repeated information) those who were in the same sessions were closely followed for SARS-CoV-2 symptoms and signs. For a week, no new patient was enrolled in that session. The data of the patients isolated due to COVID-19 diagnosis or in contact with an infected person, as well as the number of COVID-19 cases occurring within 7 days after an HBO session are given in Table 4. There were only two concurrent SARS-CoV-2 cases (transmission may have occurred during the session) in the same session. As can be seen from the data presented in Table 4, patients number 2 and 7, both receiving HBO treatment in the same session, were diagnosed with SARS-CoV-2 a week apart. Patient number 2 last participated in the session on December $1^{\text {st }}, 2020$, and was excluded from HBO session taking place on December $2^{\text {nd }}, 2020$ due to a high fever. Patient number 7 was present in the same session with patient number 2 on November $30^{\text {th }}, 2020$, and December $1^{\text {st }}, 2020$. Patient number 7 showed upper respiratory infection-like symptoms, COVID-19 was confirmed by high-resolution computed tomography (HRCT) on December $7^{\text {th }}, 2020$. The remaining 4 patients who took part in 


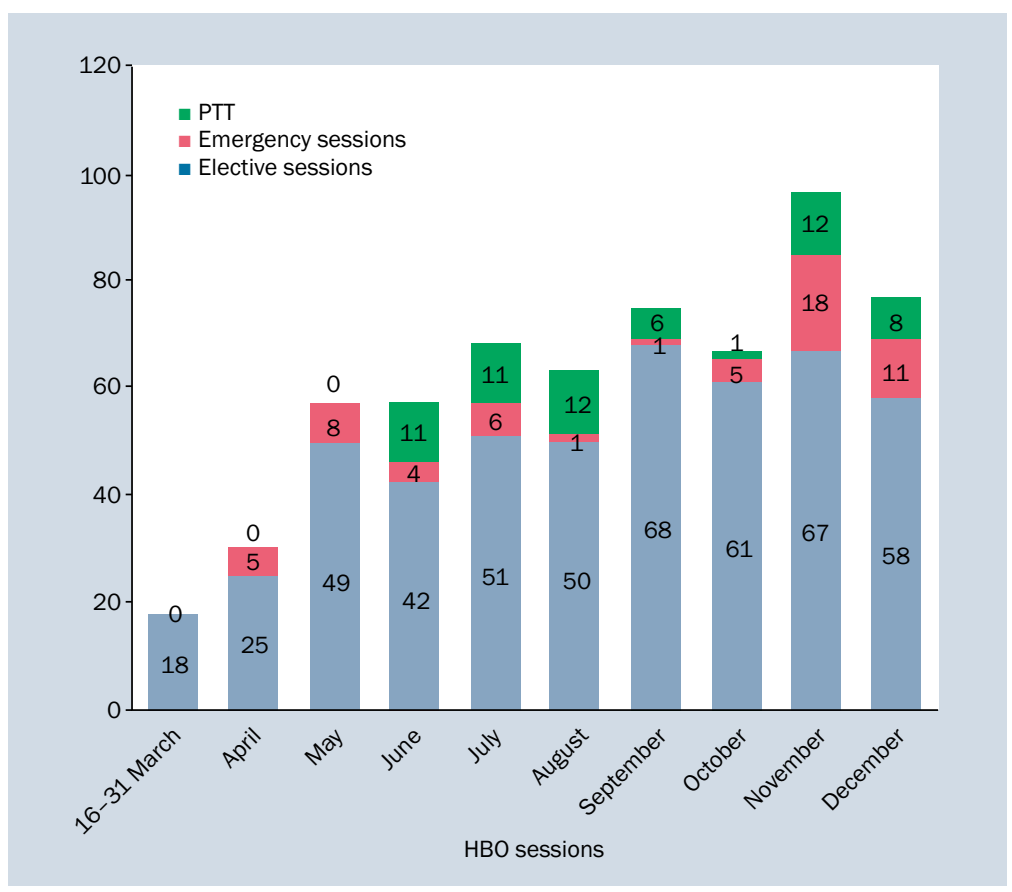

Figure 1. The overall number of hyperbaric oxygen (HBO) sessions by months (dates between March $16^{\text {th }}, 2020$ and December $31^{\text {st }}$, 2020); PTT - pressure tolerance test

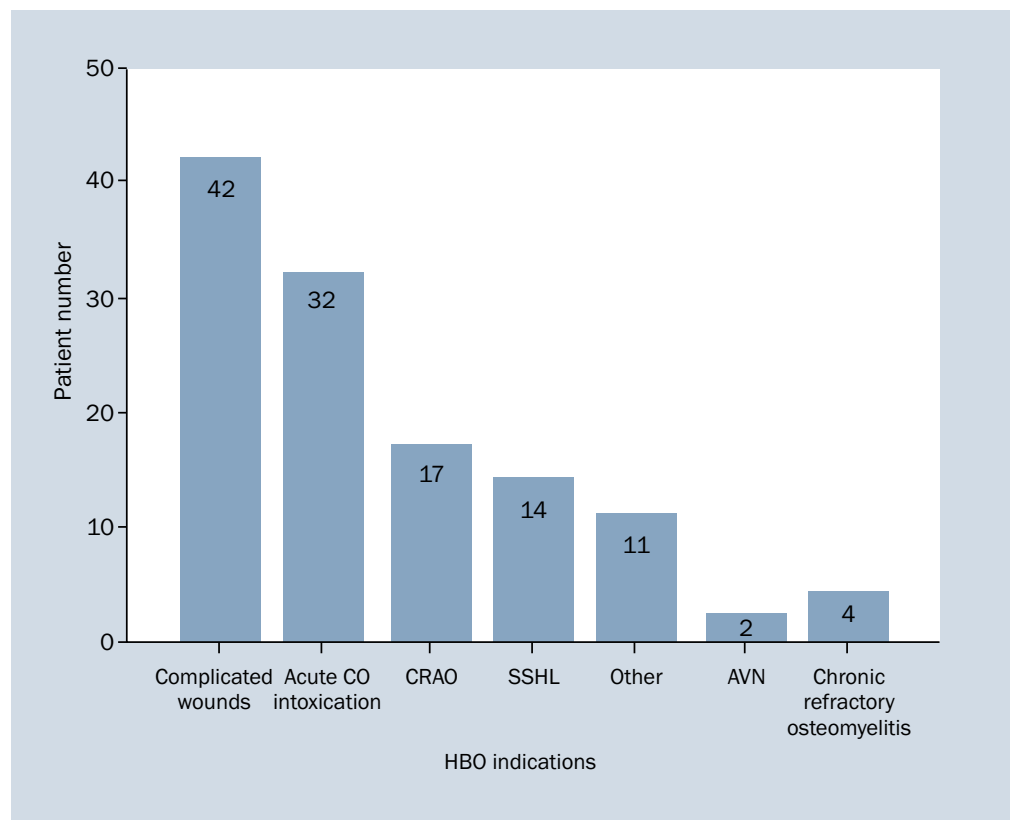

Figure 2. The distribution of patients according to hyperbaric oxygen (HBO) indications (brain abscess, radiation injury, decompression illness, spondylodiscitis, malignant otitis externa, haemorrhagic cystitis, testicular torsion were classified as "other"); CO - carbon monoxide poisoning; CRAO - central retinal artery occlusion; SSHL - sudden sensorineural hearing loss; AVN - avascular necrosis

the same session were followed for a week, but manifested no COVID-19-related symptoms or signs. New patients were admitted to the ongoing session after a week of isolation, and no other SARS-CoV-2 cases were detected in that session.
However, two inside attendants were diagnosed with SARS-CoV-2 between March $16^{\text {th }}, 2020$, and December $12^{\text {th }}, 2020$. The first person was diagnosed on August $21^{\text {st }}, 2020$, that person accompanied the HBO 
Table 3. The demographic data of patients (missing data were not included into percentage calculations)

\begin{tabular}{|c|c|c|}
\hline Parameter & $\begin{array}{l}\text { Evaluated pa- } \\
\text { tient number }\end{array}$ & $\begin{array}{l}\text { Number (\%) or } \\
\text { median (min-max) }\end{array}$ \\
\hline Age [year] & 122 & $50(2-83)$ \\
\hline Sex: & 122 & \\
\hline Male & & $71(52.8 \%)$ \\
\hline Female & & $51(41.8 \%)$ \\
\hline Body-mass index & 32 & $27.3(16.8-50.7)$ \\
\hline Chronic diseases: & 100 & $55(55 \%)$ \\
\hline $\mathrm{DM}$ & 100 & 39 (39\%) \\
\hline $\mathrm{HT}$ & 100 & $22(22 \%)$ \\
\hline CAD & 100 & $16(16 \%)$ \\
\hline PAD & 100 & $18(18 \%)$ \\
\hline CKF & 100 & $5(5 \%)$ \\
\hline Asthma & 100 & $2(2 \%)$ \\
\hline Cancer & 100 & $3(3 \%)$ \\
\hline Other & 100 & $10(10 \%)$ \\
\hline Pregnancy & 122 & $3(2.5 \%)$ \\
\hline Steroid & 96 & $17(17.7 \%)$ \\
\hline Smoking: & 68 & \\
\hline Smoker & & $14(20.6 \%)$ \\
\hline Ex-smoker & & $10(14.7 \%)$ \\
\hline Non-smoker & & $44(64.7 \%)$ \\
\hline Indications: & 122 & \\
\hline Emergency & & $68(55.7 \%)$ \\
\hline Elective & & $54(44.3 \%)$ \\
\hline $\begin{array}{l}\text { The number of HBO } \\
\text { sessions }\end{array}$ & 120 & $8.5(1-60)$ \\
\hline
\end{tabular}

Age, body mass index and the number of $\mathrm{HBO}$ sessions were not normally distributed, therefore these data were given as median (minimum-maximum) in the table; HBO - hyperbaric oxygen; DM - diabetes mellitus; HT - hypertension; $\mathrm{CAD}$ - coronary artery disease; $\mathrm{PAD}$ - peripheral artery disease; $\mathrm{CKF}$ - chronic kidney failure

session twice within 7 days before the diagnosis. The patients in the related session were followed for any SARS-CoV-2 symptoms or signs, but none of them was diagnosed with SARS-CoV-2 during the following week. The personnel member returned from holiday 4 days before being diagnosed with COVID-19, so they might have acquired the infection during the holiday. The other inside attendant was diagnosed with COVID-19 on September $29^{\text {th }}, 2020$; that person accompanied the HBO session 3 times within 7 days before the diagnosis. The patients in the same session were followed for SARS-CoV-2 symptoms or signs for a week, none of them was found to be infected with SARS-CoV-2.

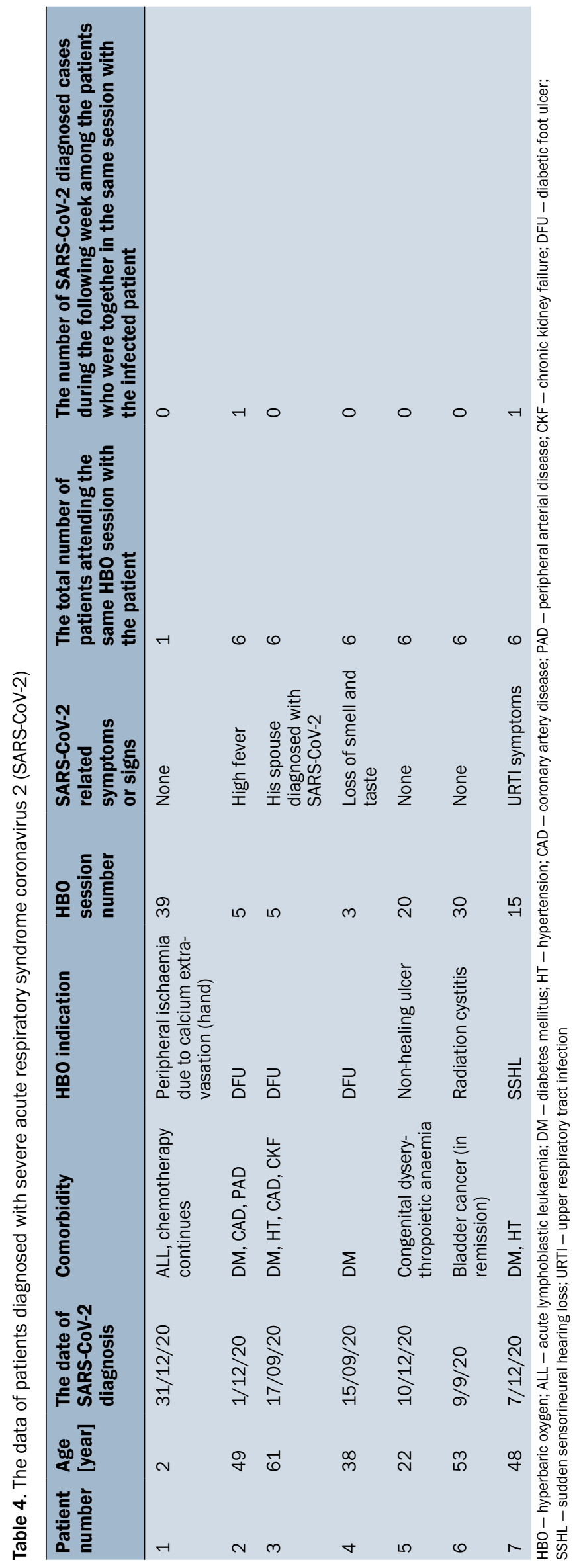




\section{DISCUSSION}

Since the official announcement of the first case on March $11^{\text {th }}, 2020$, additional preventive measures for HBO treatments were introduced in our department immediately. The rapid spread of the pandemic worldwide has caused some serious problems in terms of SARS-CoV-2 diagnosis and treatment methods. Thus, it became necessary to take precautions before the contagiousness potential was clearly identified. Obviously, the effects of the preventive measures taken during HBO treatment sessions had never been evaluated before. The measures taken in hyperbaric chambers should be different from those taken in other hospital wards. As a result of the precautions taken in our department (in line with the UHMS and ECHM recommendations) only $7(5.7 \%)$ out of 122 patients receiving HBO treatment and only $2(14.3 \%)$ out of 14 inside attendants got infected with SARS-CoV-2 between March 16 ${ }^{\text {th }}, 2020$ and December $12^{\text {th }}, 2020[17,18]$. Among the nine COVID-19 cases, only 2 people took part in the same session; they were diagnosed with COVID-19 a week apart.

The transmission of SARS-CoV-2 by aerosols and contact with contaminated surfaces poses the biggest challenge for HBO centres [19]. Patients who stay together in a closed area for about 2 hours during a routine HBO treatment in a multiplace hyperbaric chamber are definitely at risk from transmission. In our clinic, HBO patients are not routinely given a polymerase chain reaction (PCR) test for SARS-CoV-2. The patients are only asked about their symptoms and contact history with COVID-19 patients. The study showed that $5.7 \%$ patients receiving HBO treatment and $14.3 \%$ inside attendants were diagnosed with COVID-19. The inside attendants and patients were isolated after being diagnosed, and the patients they contacted were followed for symptoms and signs for a week. Among the nine COVID-19 cases, there were only 2 (22.2\%) concurrent cases; the patients were diagnosed with COVID-19 a week apart. However, after examining the sessions in which they had both participated it turned out that these 2 patients were sitting 3 seats away from each other. Another patient was sitting in between them but did not get infected with SARS-CoV-2. Therefore, there is no clear evidence that these two patients infected each other; on the contrary, since no other patient was infected with COVID-19, we may assume that this was a pure coincidence. Therefore, we believe that the measures implemented in our department suffice to prevent in-session transmission of COVID-19 and other similar infectious diseases that are transmitted from aerosols and contaminated surfaces.

On the other hand, the frequency of asymptomatic cases is controversial, and the studies on asymptomatic cases limited. The China Centre for Disease Control and Prevention report reported that 889 (1\%) of 72,314 COVID-19 cases de- tected as of February $11^{\text {th }}, 2020$, were asymptomatic [20]. The community-based proportion of seropositivity among healthy people was $4.8 \%$ in Switzerland, 5.0\% in Spain and 8.3\% in Brazil [21-23]. As can be seen from the data above, the rate of asymptomatic cases is not stable and cannot be precisely estimated. It is known that COVID-19 infection can be seen in all age groups, and most cases are mild or asymptomatic [20]. However, people aged over 65 and those with underlying diseases (obesity, cardiovascular diseases, chronic renal failure, diabetes, chronic lung disease, smokers, cancer patients, solid organ or hematopoietic stem cell transplant patients) are at risk of severe disease [19, 24]. Such patients are much more likely to require hospitalisation compared to patients without comorbidities (45.4\% vs. $7.6 \%$ ). Also, the same study showed that patients with comorbidity are 12 times more likely to succumb to the disease [20]. Considering HBO indications, most patients receiving HBO treatment are expected to be in the risk group. Remarkably, a majority of patients (59.8\%) among those receiving HBO treatment in the course of our study were considered to be at risk for severe COVID-19 presentation. It must be noted that high-risk patients were not included in HBO treatment unless there was a significant risk of organ loss. Thus, we can conclude that most patients receiving HBO treatment were unlikely to get over COVID-19 asymptomatically. We believe that unidentified asymptomatic COVID-19 cases are very rare among patients treated in our department.

Carbon monoxide intoxication and central retinal artery occlusion, considered HBO emergencies, constituted the most common indications for HBO treatment after complicated wounds. In general, most of the patients (55.7\%) received treatment on emergency basis. Therefore, we believe that we have effectively managed patient selection criteria for the first 9 months of the COVID-19 pandemic. After analysing the number of monthly HBO treatment sessions, it is clear that we had the lowest number of sessions in the first 2 months (March and April 2020) of the COVID-19 pandemic. This can be explained by the restrictions imposed throughout our country. On March 21 ${ }^{\text {st }}, 2020$, people aged 65 and over and those with chronic diseases were prohibited from leaving their homes. On March $22^{\text {nd }}, 2020$, flexible working arrangements, working from home and rotational shift work were introduced in all public institutions. On April $3^{\text {rd }}, 2020$, a curfew was imposed on those aged 20 years and under. Additional curfew measures (a 48-hour curfew during weekends) were imposed in 30 metropolitan cities by the Ministry of Internal Affairs on April $11^{\text {th }}, 2020$. These restrictions lasted by mid-May 2020, and controlled normalisation was initiated on May $11^{\text {th }}, 2020$, and afterward. Because of the restrictions there were fewer applications for HBO treatment and therefore the number of sessions was the lowest in March and April 2020 [25]. The number 
of sessions carried out in our clinic was at a similar level in the period between May and October, and the highest number of sessions $(n=97)$ was recorded in November 2020. This is mainly attributable to the winter season, when carbon monoxide intoxication cases are frequent throughout the country. However, there was a decrease in the number of sessions in December $(n=77)$ and between May and October. This decrease was also observed in the number of emergency sessions.

The main limitation of our study is the low number of COVID-19 patients, so the transmission of infections during $\mathrm{HBO}$ sessions was not evaluated statistically. Also, the lack of long-term follow-up of COVID-19 patients, besides the lack of information on the course and severity of COVID-19 cases are other study limitations.

\section{CONCLUSIONS}

Our study was the first to evaluate the effects of measures taken to prevent the COVID-19 transmission in an HBO centre. There is no data available in the literature regarding this issue. Consequently, we believe that the measures taken in our department are sufficient to prevent SARS-CoV-2 transmission in an HBO centre. The fact that there was almost no transmission during the sessions shows the efficiency of the precautions taken. Furthermore, instead of performing a PCR test in every case, asking about symptoms and contact history seems to be a sufficient precaution. Besides, the risk of a false positive results on the PCR test and limited transmission in the sessions eliminate the PCR test requirement in each case. Thus, unnecessary financial burden can be prevented.

\section{REFERENCES}

1. Zhou $P$, Yang $X L$, Wang $X G$, et al. A pneumonia outbreak associated with a new coronavirus of probable bat origin. Nature. 2020; 579(7798): 270-273, doi: 10.1038/s41586-020-2012-7.

2. Wu F, Zhao Su, Yu B, et al. A new coronavirus associated with human respiratory disease in China. Nature. 2020; 579(7798): 265-269, doi: 10.1038/s41586-020-2008-3.

3. Zhu N, Zhang $D$, Wang W, et al. A novel coronavirus from patients with pneumonia in China, 2019. N Engl J Med. 2020; 382(8): 727-733, doi: 10.1056/nejmoa2001017.

4. Coronaviridae Study Group of the International Committee on Taxonomy of Viruses. The species Severe acute respiratory syndrome-related coronavirus: classifying 2019-nCoV and naming it SARS-CoV-2. Nat Microbiol. 2020; 5(4): 536-544, doi: 10.1038/ s41564-020-0695-z, indexed in Pubmed: 32123347.

5. Huang C, Wang Y, Li X, et al. Clinical features of patients infected with 2019 novel coronavirus in Wuhan, China. Lancet. 2020; 395(10223): 497-506, doi: 10.1016/S0140-6736(20)30183-5, indexed in Pubmed: 31986264.

6. Xu Z, Shi L, Wang Y, et al. Pathological findings of COVID-19 associated with acute respiratory distress syndrome. Lancet Respir Med. 2020; 8(4): 420-422, doi: 10.1016/S2213-2600(20)30076-X, indexed in Pubmed: 32085846.
7. Vetter $P, V u$ DL, L'Huillier AG, et al. Clinical features of covid-19. BMJ. 2020; 369(m1470), doi: 10.1136/bmj.m147.

8. Kim GU, Kim MJ, Ra SH, et al. Clinical characteristics of asymptomatic and symptomatic patients with mild COVID-19. Clin Microbiol Infect. 2020; 26(7): 948.e1-948.e3, doi: 10.1016/j. cmi.2020.04.040, indexed in Pubmed: 32360780.

9. Meyerowitz EA, Richterman A, Gandhi RT, et al. Transmission of SARS-CoV-2: A Review of Viral, Host, and Environmental Factors. Ann Intern Med. 2021; 174(1): 69-79, doi: 10.7326/M20-5008, indexed in Pubmed: 32941052.

10. Morawska L, Milton DK. It is time to address airborne transmission of coronavirus disease 2019 (COVID-19). Clin Infect Dis. 2020; 71(9): 2311-2313, doi: 10.1093/cid/ciaa939, indexed in Pubmed: 32628269.

11. World Health Organization Web Site [homepage on the Internet]. Publications: Transmission of SARS-CoV-2: implications for infection prevention precautions. https://www.who.int/publications/i/item/ modes-of-transmission-of-virus-causing-covid-19-implications-for-ipc-precaution-recommendations (cited 2021 May 09).

12. Klompas M, Baker MA, Rhee C, et al. Airborne Transmission of SARS-CoV-2: Theoretical Considerations and Available Evidence. JAMA. 2020 [Epub ahead of print]; 324(5): 441-442, doi: 10.1001/ jama.2020.12458, indexed in Pubmed: 32658248.

13. Chagla Z, Hota S, Khan S, et al. International Hospital and Community Epidemiology Group. Airborne Transmission of COVID-19. Clin Infect Dis. 2020 [Epub ahead of print], doi: 10.1093/cid/ciaa1118, indexed in Pubmed: 32780799.

14. Lu J, Gu J, Li K, et al. CovID-19 Outbreak Associated with Air Conditioning in Restaurant, Guangzhou, China, 2020. Emerg Infect Dis. 2020; 26(7): 1628-1631, doi: 10.3201/eid2607.200764, indexed in Pubmed: 32240078.

15. Hamner L, Dubbel P, Capron I, et al. High SARS-CoV-2 Attack Rate Following Exposure at a Choir Practice - Skagit County, Washington, March 2020. MMWR Morb Mortal Wkly Rep. 2020; 69(19): 606-610, doi: 10.15585/mmwr.mm6919e6, indexed in Pubmed: 32407303.

16. Shen Ye, Li C, Dong H, et al. Community Outbreak Investigation of SARS-CoV-2 Transmission Among Bus Riders in Eastern China. JAMA Intern Med. 2020; 180(12): 1665-1671, doi: 10.1001/jamainternmed.2020.5225, indexed in Pubmed: 32870239.

17. Undersea and Hyperbaric Medical Society Web site. [homepage on the Internet]. "Guidelines for infection control, patient treatment, and staff safety considerations related to Hyperbaric Oxygen Therapy in monoplace and multiplace hyperbaric chambers during the novel coronavirus disease (COVID-19) outbreak". Created March 2020. https://www.uhms.org/images/MiscDocs/UHMS_Guidelines_-_COVID-19_V4.pdf (cited 2021 May 25).

18. European Committee for Hyperbaric Medicine (ECHM) Web Site. [homepage on the Internet].“EUBS \& ECHM position statement on the use of Hyperbaric Oxygen Therapy (HBOT) for the treatment of COVID-19 patients (30th April 2020). http://www.echm.org/ documents/English-ECHM-EUBS-position-on-the-use-of-HBOT-for-COVID-19-1st-May-2020.pdf (cited 2021 May 25).

19. Cascella M, Rajnik M, Aleem A, et al. Features, Evaluation, and Treatment of Coronavirus (COVID-19) [Updated 2021 Apr 20]. In: StatPearls [Internet]. Treasure Island (FL): StatPearls Publishing; 2021 Jan.

20. Wu Z, McGoogan JM. Characteristics of and Important Lessons From the Coronavirus Disease 2019 (COVID-19) Outbreak in China: Summary of a Report of 72314 Cases From the Chinese Center for Disease Control and Prevention. JAMA. 2020; 323(13): 
1239-1242, doi: 10.1001/jama.2020.2648, indexed in Pubmed: 32091533.

21. Borges LP, Martins AF, de Melo MS, et al. Seroprevalence of SARS-CoV-2 IgM and IgG antibodies in an asymptomatic population in Sergipe, Brazil. Rev Panam Salud Publica. 2020; 44: e108, doi: 10.26633/RPSP.2020.108, indexed in Pubmed: 33042199.

22. Pollán M, Pérez-Gómez B, Pastor-Barriuso R, et al. ENE-COVID Study Group. Prevalence of SARS-CoV-2 in Spain (ENE-COVID): a nationwide, population-based seroepidemiological study. Lancet. 2020; 396(10250): 535-544, doi: 10.1016/S0140-6736(20)31483-5, indexed in Pubmed: 32645347.
23. Stringhini S, Wisniak A, Piumatti G, et al. Seroprevalence of anti-SARS-CoV-2 IgG antibodies in Geneva, Switzerland (SEROCoV-POP): a population-based study. Lancet. 2020; 396(10247): 313-319, doi: 10.1016/S0140-6736(20)31304-0, indexed in Pubmed: 32534626.

24. Stokes EK, Zambrano LD, Anderson KN, et al. Coronavirus Disease 2019 Case Surveillance - United States, January 22-May 30, 2020. MMWR Morb Mortal Wkly Rep. 2020; 69(24): 759-765, doi: 10.15585/mmwr.mm6924e2, indexed in Pubmed: 32555134.

25. Wikipedia Web site. [homepage on the Internet]. "Türkiye'de COVID-19 pandemisi zaman çizelgesi” . https://tr.wikipedia.org/wiki/ Türkiye\%27de_COVID-19_pandemisi_zaman_çizelgesi\#Mart_2020 (cited 2021 May 25). 